\title{
Competato
}

\section{Bibliografias em Pernambuco: panorama histórico (1960-2018)}

\author{
Murilo Artur Araújo da Silveira \\ Doutor; Universidade Federal de Pernambuco, Recife, PE, Brasil; \\ muriloas@gmail.com
}

\begin{abstract}
Resumo: Este artigo estabelece o panorama histórico das bibliografias produzidas, editadas e difundidas de, sobre e em Pernambuco. O argumento que justifica o estudo é a diversidade e pluralidade de registros, de enfoques, de arranjos e categorizações e de coberturas temáticas, diante do conjunto de manifestações socioculturais presentes no Estado de Pernambuco. Tem como objetivo central caracterizar o conjunto das bibliografias produzidas e difundidas de, sobre e em Pernambuco, de 1960 a 2018. Configura-se com uma pesquisa bibliográfica e descritiva que se viabiliza pelas técnicas de análise bibliográfica e documental. Apresentam-se as bibliografias produzidas, editadas e disseminadas por meio do arranjo retrospectivo, em que se destacam: a) os protagonismos de Lúcia Gaspar e da Editora Universitária da UFPE enquanto organizadora e editora, respectivamente, no período; e b) a diversidade de temas e as formas de concepção e elaboração das bibliografias. Conclui que o Estado de Pernambuco por meio das bibliografias analisadas está bem representado no que concerne às suas manifestações e práticas socioculturais.
\end{abstract}

Palavras-chave: Bibliografias. Repertórios bibliográficos. Pernambuco. História.

\section{Introdução}

A organização, produção e difusão de repertórios bibliográficos são atividades e processos complexos, que exigem esforço intelectual, articulação entre saberes teóricos e técnicos e demandam acesso irrestrito às fontes de informação. Em linhas gerais, entende-se por repertórios bibliográficos o conjunto de elementos sinalizadores de documentos primários e secundários, categorizados por um arranjo e descritos na forma de listas e/ou referências bibliográficas. Em uma visão mais ampla, e também mais contemporânea, os repertórios bibliográficos são, por um lado, produtos documentais descritivos e temáticos de fontes de informação e, do outro, instrumentos mediadores da herança cultural produzida 
e difundida por pessoas, instituições, governos, países e organismos nacionais e internacionais.

Os destaques nos termos produtos e instrumentos são para demonstrar que a produção, organização e disseminação dos repertórios bibliográficos: (a) intensificam a discussão sobre a compreensão de documento, suas conceituações e funções clássicas e contemporâneas (SALDANHA, 2013); (b) ampliam a articulação entre saberes e fazeres teóricos, técnicos e tecnológicos vinculados ao tema em uma perspectiva integrada (LARA, 2018); e (c) sinalizam a transversalidade das relações reais e potenciais com outros campos, domínios e áreas de especialidade na proposição dos produtos (CRIPPA, 2015; ARAÚJO, 2018).

As formas mais comuns de repertórios bibliográficos, enquanto produtos e instrumentos, são as bibliografias e os catálogos. Cunha e Cavalcanti (2008) indicam que as bibliografias são repertórios bibliográficos que são produções sistemáticas de listas descritivas de fontes de informação para fins de recuperação (p. 46). Já para o conceito de catálogo, os referidos autores mencionam que tais repertórios são documentos secundários que registram e descrevem documentos reunidos permanentemente ou temporariamente (p. 71). Nota-se que, em ambas as descrições, as bibliografias e os catálogos pouco se diferem conceitualmente.

Contudo, é oportuno destacar que há diferenças sutis e que se torna necessário apontá-las:

a) as bibliografias são listas parciais de um conjunto de documentos que compõem os acervos e as coleções; e

b) os catálogos são listas completas de um conjunto de documentos que compõem os acervos e as coleções.

As características de parcialidade e completude podem ser percebidas ao longo dos extensos verbetes apontados por Cunha e Cavalcanti (2008), como também na breve descrição destacada no parágrafo anterior. Nesse sentido, defende-se que a diferença entre bibliografias e catálogos reside na dicotomia entre a parcialidade e a completude na composição das listas e, por conseguinte, nas manifestações materiais enquanto repertórios. As referências bibliográficas 
dos artigos (bibliografias) e os catálogos de exposição (catálogos) são bons exemplos que explicitam essas distinções.

Ao considerar a característica da parcialidade das bibliografias, esses repertórios de registros bibliográficos adquirem funções também parciais que, mesmo na totalidade de um conjunto de itens, nunca indicará a completude do que é parcial. Nesse sentido, depõe Fonseca (1964) que as bibliografias, embora se configurem como obras de referências exaustivas e completas em sua ordenação de itens, elas expressarão um viés parcial de uma coleção ou de um organizador. Todavia, a função de uma bibliografia tem relação direta com o propósito da compilação dos itens bibliográficos, pois podem adquirir outras funções e fornecer outras respostas aos usuários, mesmo sem terem sido concebidas como tal (HARTNESS, 2014).

Sobre a função da bibliografia, Nogueira (2016, p. 153) enfatiza que

a bibliografia, enquanto produto gerado pela ordenação de documentos, exerce a função de disponibilizar dados e também o roteiro para acesso aos originais, permitindo que se faça análises (dependendo do caso, de longo período) sobre autores, editores, livreiros, tipógrafos, impressores e outros agentes da cadeia produtiva do livro, tão caros aos estudos na área.

Já Araújo (2008) complementa que a elaboração de levantamentos bibliográficos, catálogos e inventários são também fundamentais para remontar e rememorar os registros do passado para o presente, de forma que se lance para o futuro, a partir da função de controle bibliográfico que esses documentos adquirem. A autora enfatiza ainda que as instituições e as categorias profissionais que se dedicam à guarda, organização, preservação e disseminação de bens culturais têm a obrigação social de fornecer produtos documentais que permitam serem recuperadas passagens históricas, tradições, narrativas e interpretações advindas desses registros. Assim, as bibliografias permitem reconstruir memórias parciais dos registros do passado e adquirem, nessa perspectiva, uma função pretérita que se materializa por meio da compilação bibliográfica com propósitos temáticos definidos.

Para Prysthon, Silveira e Silva (2008 p. 99), as bibliografias 
podem ser entendidas como os guias de fontes de informações que assinalam temas, pessoas, instituições, locais, identificando seus dados descritivos e temáticos, localizando-os fisicamente, através de arranjo alfabético, cronológico, temático, entre outros, concomitantemente ou não.

No escopo da discussão empreendida, questiona-se: como se configura a produção e difusão de bibliografias de, sobre e no Estado de Pernambuco? Como produtos e instrumentos, quais as características fundamentais e diferenciais desses repertórios? Como pressupostos iniciais, a pesquisa admite o protagonismo dos bibliotecários e das instituições públicas como produtores e editores de bibliografias, assim como a ocorrência significativa de fontes, coleções e acervos presentes nas unidades de informação mantidas pelas instituições públicas e privadas presentes no Estado. Admite-se encontrar, também, uma considerável diversidade e pluralidade de registros, de enfoques, de arranjos e categorizações e, ainda, de coberturas temáticas gerais e especializadas, diante do conjunto de manifestações socioculturais presentes em Pernambuco.

Dessa forma, o objetivo central da contribuição é caracterizar o conjunto das bibliografias produzidas e difundidas de, sobre e em Pernambuco, de 1960 a 2018. Desdobram-se em específicos:

a) estabelecer a cronologia da produção das bibliografias em uma perspectiva diacrônica; e

b) mapear os autores, as instituições, as editoras e as características descritivas e o escopo temático (arranjo) das obras registradas nas bibliografias.

A realização da pesquisa se torna importante porque se adjunta ao conjunto de outros estudos, de cunho aplicado, que sinaliza o panorama de produções e edições de bibliografias de/sobre o Brasil. Mais ainda, os resultados indicarão os caminhos percorridos, as contribuições efetuadas e os retratos bibliográficos que se fomentaram e se desenvolveram em Pernambuco por mais de cinquenta anos. Também pretende apontar o compromisso social dos sujeitos e das instituições na oferta de produtos bibliográficos às comunidades que atendem. Por fim, mas não menos importante, busca-se destacar os elementos 
que constituem o movimento pernambucano na elaboração de repertórios bibliográficos em um contexto sociocultural favorável para a editoração e difusão desses.

\section{Percurso metodológico}

Esta contribuição se configura como uma pesquisa do tipo bibliográfica e descritiva, por se tratar do estabelecimento do panorama histórico evidenciado dos levantamentos bibliográficos realizados de, sobre e no Estado de Pernambuco, de 1960 a 2018. Utiliza-se das técnicas de análise bibliográfica e documental para coleta, organização e análise dos dados e informações presentes nos repertórios encontrados.

No que concerne à coleta dos repertórios bibliográficos, é importante frisar que parte considerável das fontes fazem parte da coleção particular do autor. No entanto, foram realizadas consultas, de 30 de novembro a 04 de dezembro de 2018, aos catálogos digitais da Universidade Federal de Pernambuco (UFPE), da Universidade Federal Rural de Pernambuco (UFRPE), da Universidade de Pernambuco (UPE), da Universidade Católica de Pernambuco (UNICAP) e da Fundação Joaquim Nabuco (FUNDAJ). Apesar de constar na lista prévia de bibliotecas para consulta, a Biblioteca Pública do Estado de Pernambuco (BPE) não pôde ser considerada, uma vez que não foi encontrado o catálogo digital da unidade em seu sítio oficial na Internet.

Das buscas realizadas nos catálogos digitais das referidas bibliotecas, cinco documentos novos foram encontrados e três deles estavam disponíveis em mais de uma biblioteca. Após a identificação, o autor foi às bibliotecas que dispunham dos cinco itens e coletou as informações descritivas e temáticas necessárias para as análises.

De posse dos registros, suas informações e seus elementos descritivos e temáticos, realizou-se a organização conforme a distinção de repertórios bibliográficos baseada nas proposições de Noronha (1982) e Cunha (2001), optando-se pelas seguintes:

a) retrospectiva: disposição de documentos por data de publicação; 
b) sistemática: disposição de documentos pela cobertura dos assuntos e suas subdivisões; e

c) geográfica: disposição dos documentos de acordo com o tratamento geográfico e/ou designação institucional.

As análises também seguiram as proposições de Noronha (1982) e Cunha (2001), baseando-se nas seguintes distinções quanto à natureza das bibliografias encontradas:

a) primárias: listagem de documentos referente a textos originais (bibliografias nacionais, guias de fontes de informação);

b) secundárias: listagem de documentos secundários e terciários (bibliografia de bibliografia);

c) analíticas: listagem de documentos referente a textos originais, seguidas de comentários e/ou análises (periódicos de resumo);

d) sinaléticas: listagem de documentos que se organizam na forma sequenciada de referências;

e) correntes ou periódicas: listagem de documentos que se baseia em períodos de tempo pré-estabelecidos (bibliografias nacionais, periódicos de resumo);

f) retrospectivas: listagem de documentos que se baseia, exclusivamente, em um período de tempo já ultrapassado;

g) seletivas: listagem de documentos que se dedicam a um conjunto de itens e/ou partes de coleções específicas a partir de um critério de seleção (catálogos de obras raras, de produtos agrícolas); e

h) exaustivas: listagem exaustiva de documentos referente a uma ou várias coleções.

É importante pontuar que as proposições de Noronha (1982) e Cunha (2001) não devem ser consideradas como exclusivas, já que em muitos resultados, as bibliografias encontradas transitam em mais de uma distinção quanto à sua organização e constituição.

Os elementos temáticos e descritivos das bibliografias encontradas foram sistematizadas por décadas (organização retrospectiva) com base nos seguintes rótulos (organização sistemática): 


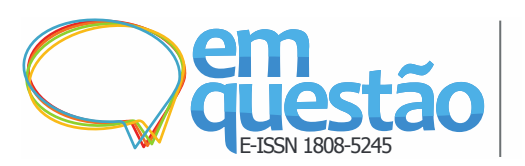
a) imagem da capa;
b) organização da bibliografia;
c) título da bibliografia;
d) editora;
e) data de publicação (ano);
f) classificação da bibliografia; e
g) comentários sobre a bibliografia.

\section{Bibliografia em Pernambuco: análise retrospectiva e sistemática}

Após a coleta e organização dos dados referente às bibliografias, chegou-se ao total de dezesseis registros. Enfatiza-se que as bibliografias encontradas foram publicadas por editoras públicas e privadas, com organização definida e com os demais elementos descritivos e temáticos bem definidos.

Para a apresentação e discussão dos resultados, optou-se pela análise retrospectiva, no primeiro momento, já que o objetivo do texto é situar historicamente a produção das bibliografias de, sobre e em Pernambuco. Em cada momento cronológico, as bibliografias serão apresentadas de forma sistemática, para que as mesmas possam ser caracterizadas conforme os preceitos teóricos sustentados pelo campo.

Os períodos demarcados para a apresentação das bibliografias encontradas foram:

1) Os primórdios;

2) Os anos dourados;

3) Novos rumos.

O momento denominado os primórdios, remete às décadas de 1960 e 1970; já o momento os anos dourados se concentra nas décadas de 1980 e 1990; e, o momento novos rumos sinaliza as produções das décadas de 2000 e 2010 (até o ano de 2018).

\subsection{Bibliografias em Pernambuco: os primórdios (1960-1970)}

O período que compreende as décadas de 1960 e 1970 abarca apenas duas bibliografias encontradas nas bibliotecas mencionadas. Além disso, as duas 
obras são da década de 1960, ambas organizadas por bibliotecários e editadas pela Imprensa Universitária da UFPE.

O Quadro 1, abaixo, apresenta as características das bibliografias do período.

Quadro 1: Características das Bibliografias: os primórdios (1960-1970)

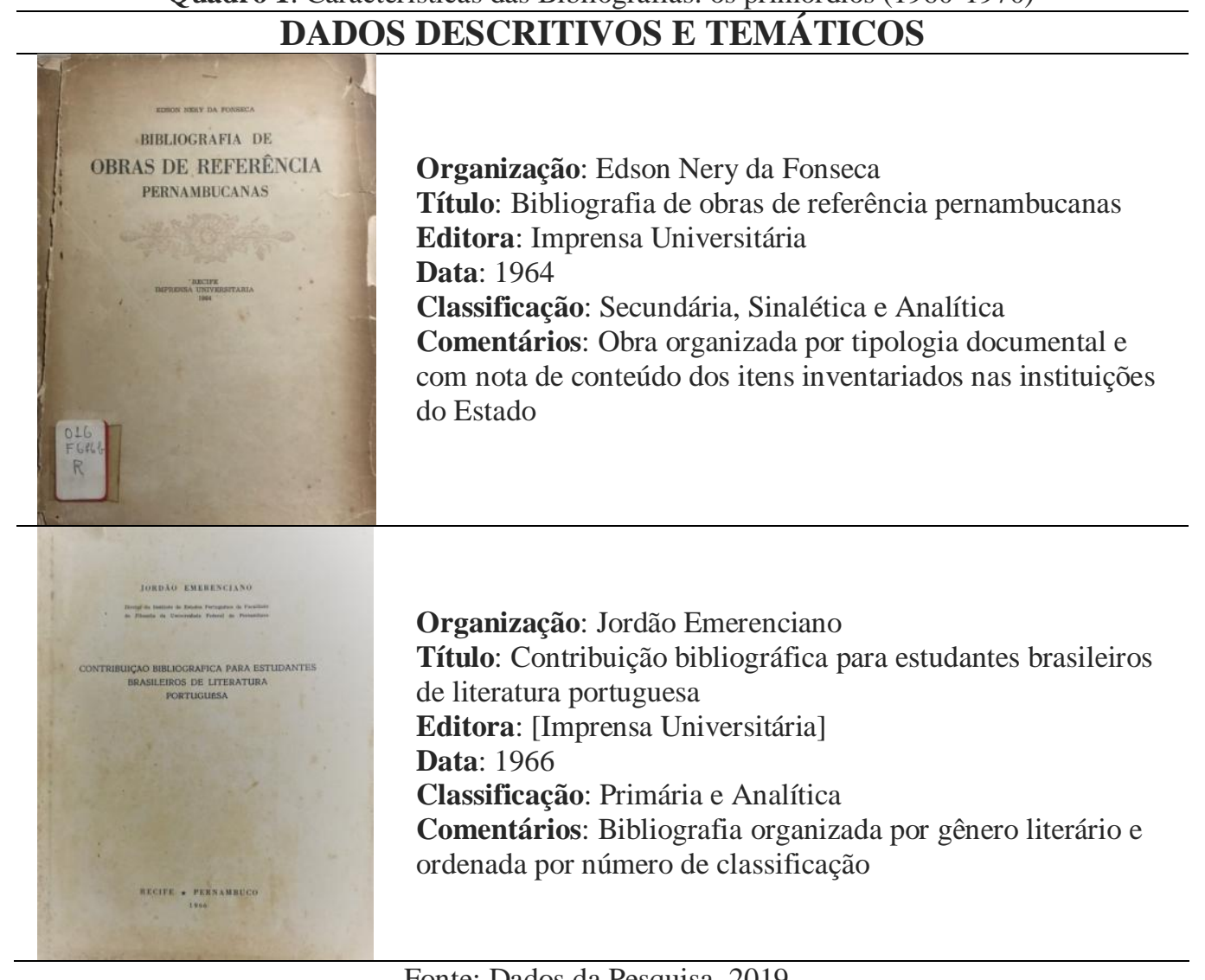

Fonte: Dados da Pesquisa, 2019.

O quadro revela que os dois organizadores destacados foram professor (Edson Nery da Fonseca) e aluno (Jordão Emerenciano) da primeira turma do Curso de Biblioteconomia da então denominada Universidade do Recife (que logo depois se tornou Universidade Federal de Pernambuco) e ambas as obras foram publicadas pela Imprensa Universitária. Verifica-se também que as bibliografias são analíticas porque estabelecem sínteses documentárias dos itens listados, embora se dediquem a tipologias documentais distintas.

\subsection{Bibliografias em Pernambuco: os anos dourados (1980-1990)}

O período que compreende as décadas de 1980 e 1990 concentra a produção e publicação de oito bibliografias. Das oito bibliografias, somente uma não é 
assinada por pessoas e três são assinadas por um profissional ligados às Ciências Humanas.

O quadro 2 apresenta as características das oito bibliografias do período.

Quadro 2: Características das Bibliografias: os anos dourados (1980-1990)

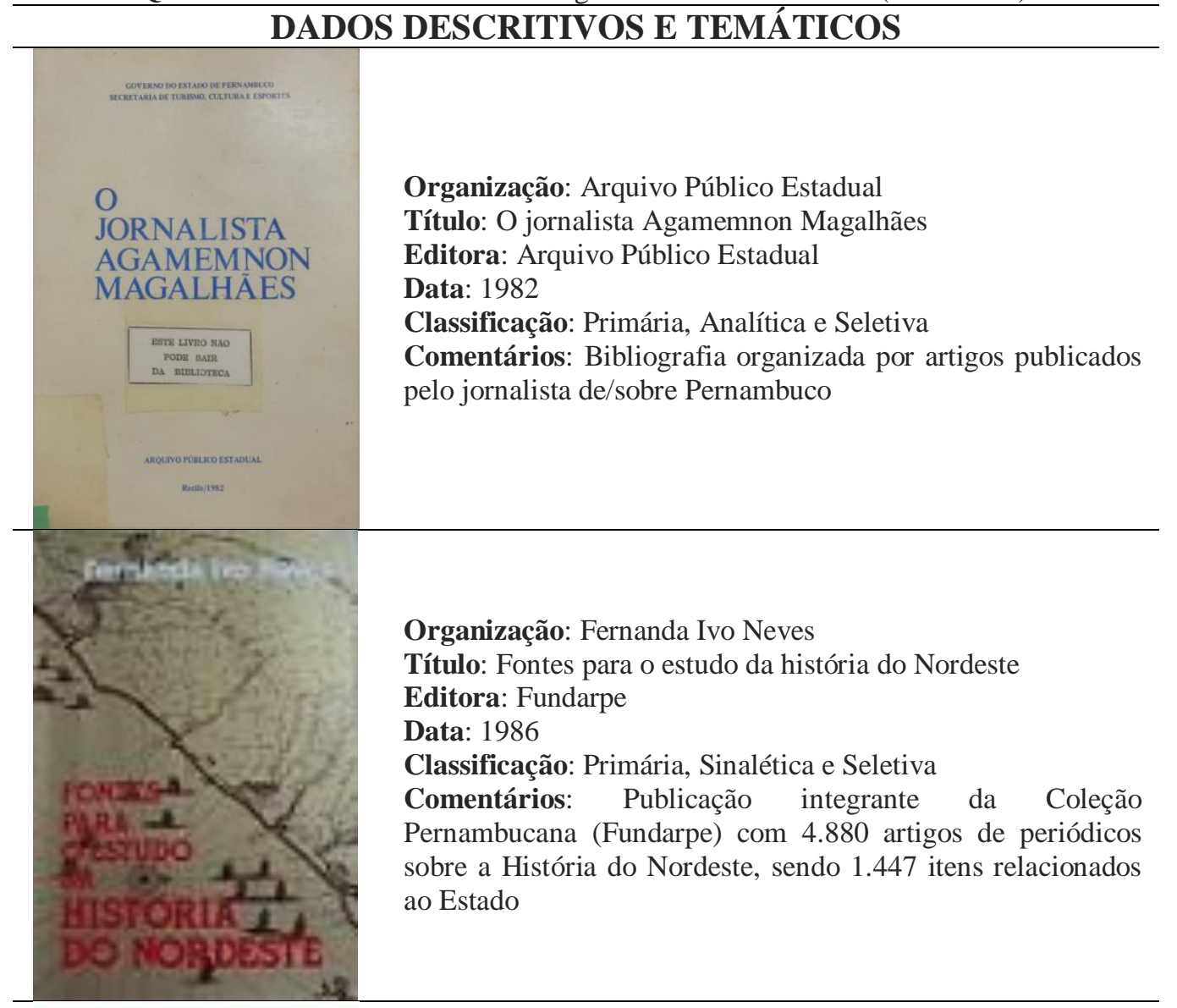

Viajantes Franceses

NO BRASIL Gilda Maria Whitaker Verri

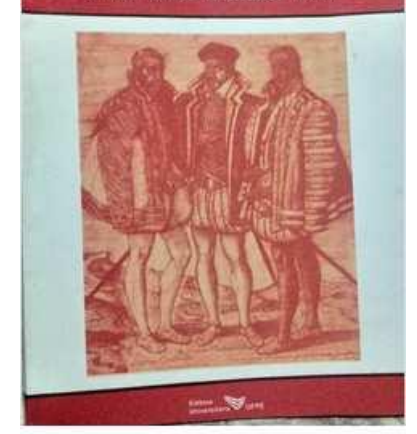

Organização: Gilda Maria Whitaker Verri

Título: Viajantes franceses no Brasil

Editora: Editora Universitária da UFPE

Data: 1994

Classificação: Primária, Sinalética e Seletiva

Comentários: Bibliografia de obras relacionadas às viagens francesas ao Brasil existentes nas bibliotecas especializadas de Pernambuco, no Brasil e no Mundo 


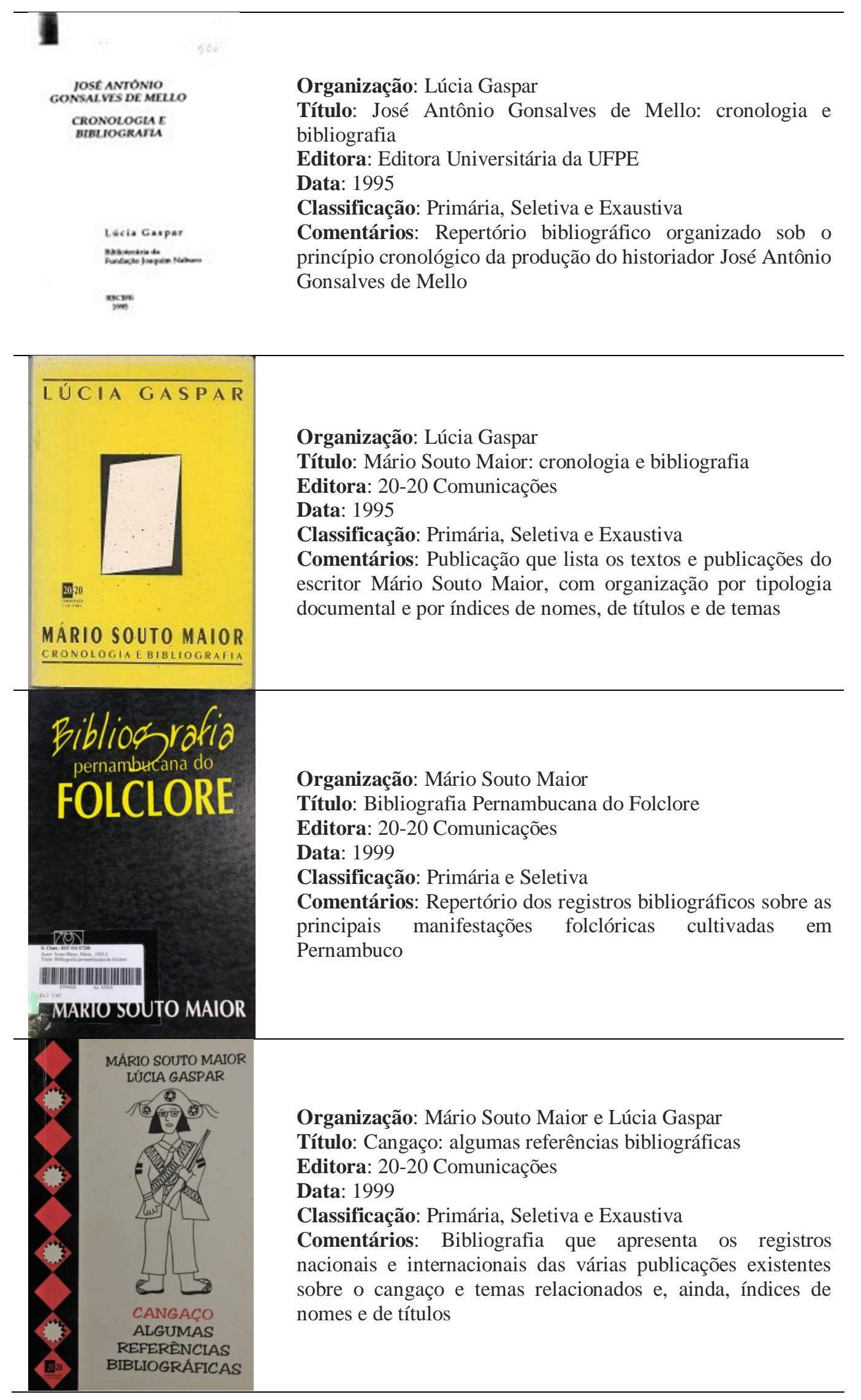




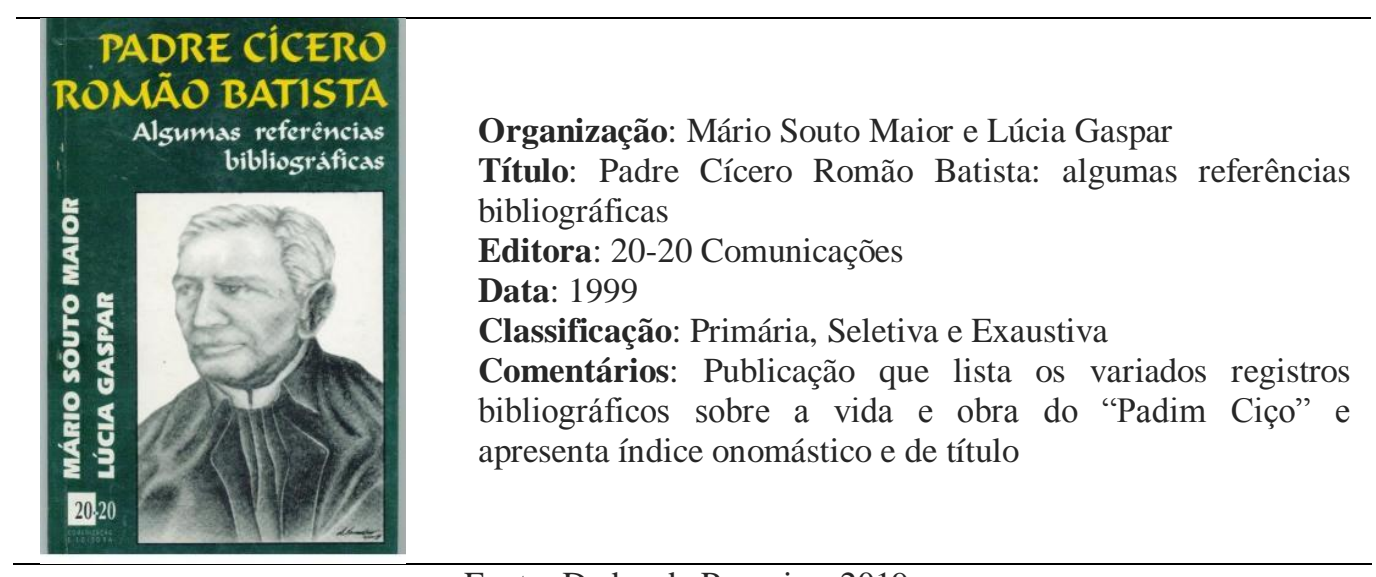

Fonte: Dados da Pesquisa, 2019.

O quadro destaca a presença do escritor Mário Souto Maior em três publicações, sendo duas delas assinadas com a bibliotecária Lúcia Gaspar. A referida bibliotecária também organizou, individualmente, mais duas obras, totalizando quatro repertórios bibliográficos no momento denominado os anos dourados. Aponta-se também duas bibliografias organizadas por professoras do Departamento de Biblioteconomia da Universidade Federal de Pernambuco, Fernanda Ivo Neves e Gilda Maria Whitaker Verri.

No plano editorial, merece destaque a Editora Universitária da UFPE e a 20-20 Comunicações, com duas e quatro obras editadas, respectivamente, no período. Nota-se ainda que personagens importantes para o Estado foram tipificados em quatro bibliografias e que temas transversais como História da Região Nordeste e o Cangaço, que englobam vários Estados do Nordeste (incluindo o Estado de Pernambuco), foram recorrentes em duas bibliografias. Além disso, verifica-se que $75 \%$ das obras que caracterizam o momento os anos dourados foram publicadas na década de 1990.

\subsection{Bibliografias em Pernambuco: novos rumos (2000-2010)}

O período que compreende as décadas de 2000 e 2010 agrupa seis bibliografias do total encontrado pela pesquisa. Das seis bibliografias, percebe-se que somente em uma é que a assinatura da organização é individual e um equilíbrio de organização entre professores e bibliotecários de Pernambuco.

O Quadro 3, abaixo, apresenta as características das seis bibliografias do período. 
Quadro 3: Características das Bibliografias: novos rumos (2000-2010)

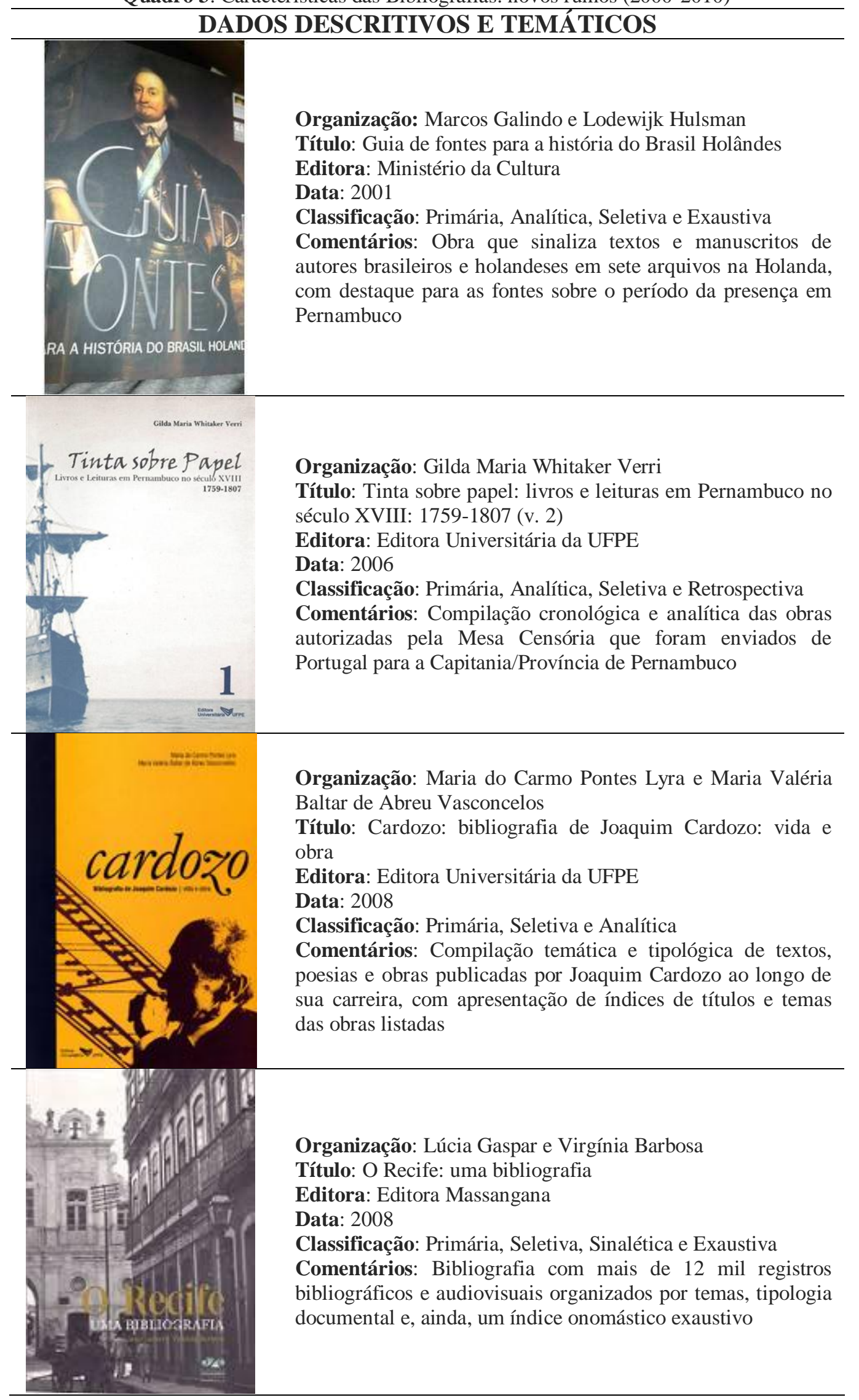




Organização: Susana Schmidt, Cecília Prysthon e Murilo
Artur Araújo da Silveira
Título: Pernambuco em fontes de informação
Editora: Editora Universitária da UFPE
Data: 2011
Classificação: Primária, Seletiva, Sinalética e Analítica
Comentários: Bibliografia analítica de 600 registros de e
sobre Pernambuco, arranjadas em 20 categorias temáticas,
além da apresentação de localização nas bibliotecas da Cidade
do Recife

Fonte: Dados da Pesquisa, 2019.

Sobre os organizadores, o quadro aponta que há uma pluralidade de pessoas e vínculos institucionais, mas a bibliotecária Lúcia Gaspar figura como a organizadora de destaque no período com duas ocorrências. Verifica-se a presença de cinco professores do Departamento de Ciência da Informação da UFPE como organizadores, tanto em conjunto quanto individualmente. Além disso, registra-se também a presença de um pesquisador holandês, em conjunto com o professor Marcos Galindo, como organizador no momento novos rumos.

Do ponto de vista da publicação, a Editora Universitária da UFPE e a Massangana figuram como as principais, com três e duas publicações no período, respectivamente. Sobre as décadas, há um equilíbrio da distribuição com quatro na década de 2000 e duas na década de 2010.

No que se refere às temáticas abarcadas nos repertórios, verifica-se que o aspecto geográfico foi o mais recorrente (com três obras), seguido pelo argumento de homenagem a personagens ligados ao Estado de Pernambuco (Joaquim Cardozo e Gilberto Freyre). Nota-se ainda que do ponto de vista da natureza das bibliografias do período, as características mais recorrentes foram as seletivas, analíticas e exaustivas. Há de se destacar também a coautoria na 
organização das bibliografias no período, seguindo uma tendência de crescimento desse fenômeno nas Ciências Humanas e Sociais nas duas últimas décadas.

\section{Comentários finais}

Os aspectos bibliográficos sobre a produção e publicação de bibliografias no Estado de Pernambuco, suas circunstâncias e características, sinalizam os objetivos desta pesquisa. Diante do exposto, acredita-se que eles foram atendidos porque se visualizou os elementos descritivos e temáticos que compõem os dezesseis repertórios bibliográficos encontrados. Contudo, há alguns comentários que merecem ser pontuados. São eles:

a) o fôlego dos profissionais, professores e instituições que se dedicaram à realização de atividades de controle documental das fontes de informação de, sobre e em Pernambuco;

b) a dinâmica bibliográfica instalada no Estado de Pernambuco indica que há uma significativa contribuição, mas há também muitas lacunas temporais entre as publicações encontradas;

c) a devoção bibliográfica de Lúcia Gaspar com mais de cinco bibliografias publicadas em quase quarenta anos de atividades como bibliotecária numa instituição renomada e preocupada com a preservação dos registros do conhecimento pertencentes ao Estado (FUNDAJ);

d) a confiança editorial das Editoras da UFPE (Imprensa Universitária e Editora Universitária da UFPE) e da FUNDAJ (Massangana) com a conferência de seus selos nas publicações que registram os levantamentos exaustivos dos registros existentes sobre o Estado de Pernambuco;

e) a pluralidade e a diversificação de temas e os argumentos na elaboração das bibliografias também é notada, configurando-se, estas publicações, muitas vezes, como homenagens a personalidades, instituições e aos elementos socioculturais presentes no lastro histórico desenvolvido e cultivado no território pernambucano; 
f) o trabalho intelectual percebido e registrado pelos organizadores deve ser também destacado, já que mais de $50 \%$ das bibliografias foram concebidas e elaboradas sob o ponto de vista analítico (bibliografias seletivas, analíticas e exaustivas).

Todavia, é importante enfatizar que podem existir mais bibliografias de, sobre e em Pernambuco que, por conta das limitações da pesquisa, não puderam compor o corpus analisado neste artigo. Acredita-se que outros levantamentos podem estar presentes na Biblioteca Pública do Estado de Pernambuco, por ser ela a unidade de depósito legal no Estado. Além disso, torna-se importante expandir o escopo para outras unidades da cidade do Recife, como também para as da Região Metropolitana.

Como sugestão para futuras pesquisas, é importante realizar estudos com os catálogos publicados sobre as coleções e acervos existentes no Estado de Pernambuco. Na busca realizada, identificou-se muitos repertórios dessa natureza e que não foram devidamente analisados em seu conjunto.

\section{Referências}

ARAÚJO, C. A. A. O que é ciência da informação. Belo Horizonte: KMA, 2018.

ARAÚJO, R. C. B. Apresentação. In: GASPAR, L.; BARBOSA, V. O Recife: uma bibliografia. Recife: Massangana, 2008. p. 5-11.

CRIPPA, G. A arte da bibliografia: ferramentas históricas, problemas metodológicos e práticas contemporâneas. Informação \& Informação, Londrina, v. 20, n. 2, p. i-vi, 2015.

CUNHA, M. B. Para saber mais: fontes de informação em ciência e tecnologia. Brasília: Briquet de Lemos, 2001.

CUNHA, M. B.; CAVALCANTI, C. R. O. Dicionário de Biblioteconomia e Arquivologia. Brasília: Briquet de Lemos, 2008.

FONSECA, E. N. Bibliografia de obras de referência pernambucanas. Recife: Imprensa Universitária, 1964.

HARTNESS, A. Brasil: obras de referência, 1999-2013: uma bibliografia comentada. Brasília: Briquet de Lemos, 2014. 
LARA, M. L. G. Conceito de bibliografia, ou conceitos de bibliografia? Informação \& Informação, Londrina, v. 23, n. 2, p. 127-151, 2018.

NOGUEIRA, W. A. "O livro como uma força na História": a bibliografia como fonte de informação e método de pesquisa. InCID: Revista de Ciência da Informação e Documentação, Ribeirão Preto, SP, v. 7, n. esp, p. 152-164, 2016.

NORONHA, D. P. O ensino de bibliografia por módulo. Revista da Escola de Biblioteconomia da UFMG, Belo Horizonte, v. 11, n. 1, p. 53-72, mar. 1982.

PRYSTHON, C.; SILVEIRA, M. A. A.; SILVA, L. S. O mundo pernambucano através de fontes de informação: 1965-2003. Informação \& Informação, Londrina, v. 13, n. 2, p. 96-107, 2008.

SALDANHA, G. S. O documento e a "via simbólica": sob a tensão da "neodocumentação". Informação Arquivística, Rio de Janeiro, v. 2, n. 1, p. 6588, 2013.

\title{
Bibliographies in Pernambuco: historical panorama (1960-2018)
}

\begin{abstract}
This article establishes the historical panorama of the bibliographies produced, edited and disseminated from, about and in Pernambuco. The argument justifying the study is the diversity and plurality of records, approaches, arrangements and categorizations and thematic coverage, in front of the set of sociocultural manifestations present in the State of Pernambuco. Its main objective is to characterize the set of bibliographies produced and disseminated from, over and in Pernambuco from 1960 to 2018. It is configured with a bibliographical and descriptive research that is made possible by the techniques of bibliographic and documentary analysis. It presents the bibliographies produced, edited and disseminated through the retrospective arrangement, in which the following stand out: a) the roles of Lúcia Gaspar and Editora Massangana as organizer and editor, respectively, in the period; and b) the diversity of themes and the ways of designing and preparing bibliographies. It concludes that the State of Pernambuco through the bibliographies analyzed is well represented in terms of its socio-cultural manifestations and practices.
\end{abstract}

Keywords: Bibliographies. Bibliographic repertoires. Pernambuco. History. 